\title{
Placenta Ingestion Enhances Analgesia Produced by Vaginal/Cervical Stimulation in Rats
}

\author{
MARK B. KRISTAL, ${ }^{1}$ ALEXIS C. THOMPSON \\ Department of Psychology, SUNY at Buffalo, Amherst, NY 14226 \\ STEVE B. HELLER AND BARRY R. KOMISARUK \\ Institute of Animal Behavior \\ Rutgers-the State University, Newark, NJ 07102
}

Received 12 August 1985

\begin{abstract}
KRISTAL, M. B., A. C. THOMPSON, S. B. HELLER AND B. R. KOMISARUK. Placenta ingestion enhances analgesia produced by vaginal/cenical stimulation in rats. PHYSIOL BEHAV 3616) 1017-1020. 1986.-Ingestion of placenta has previously been shown to enhance opiate-mediated analgesia (measured as tail-flick latency) induced either by morphine injection or by footshock. The present study was designed to test whether placenta ingestion would enhance the partly opiate-mediated analgesia produced by vaginal/cervical stimulation. Nulliparous Sprague-Dawley rats were tested for analgesia, using tail-flick latency, during and after vaginal/cervical stimulation; the tests for vaginal/cervical stimulation-induced analgesia were administered both before and after the rats ate placenta or ground beef. Placenta ingestion, but not beef ingestion. significantly heightened vaginal/cervical stimulation-induced analgesia. A subsequent morphine injection provided evidence that, as in a previous report, placenta ingestion, but not beef ingestion. enhanced - morphine-induced analgesia.
\end{abstract}

Placenta Pain Opiates Vaginal stimulation-produced analgesia Tail-flick test Afterbirth Analgesia Parturition Placentophagia VSPA Vaginal/cervical stimulation

PLACENTOPHAGIA, ingestion of the afterbirth and associated fluids, is a conspicuous feature of parturition in most species of placental mammals. Until recently, despite speculation, a demonstration of any benefit of the behavior had been elusive [5]. In 1985, however, evidence was presented that ingestion of placenta produced a significant enhancement of opiate-mediated analgesia [7]. Both morphineinduced and footshock-induced analgesia were enhanced by ingestion of placenta, whereas ingestion of cookie mash or beef was ineffective. Placenta ingestion alone did not produce analgesia. Finally, since hindpaw shock-induced analgesia is partly mediated by opiates [10], treatment with the opiate antagonist naltrexone not only attenuated the analgesia produced by hindpaw shock, as expected, but also eliminated the enhancement produced by the ingestion of placenta.

Vaginal/cervical stimulation has been shown to produce a powerful, reliable, and stimulus-bound analgesia $[2,4]$ that, like the analgesia produced by hind-paw shock, is partly opiate mediated [9]. The present study was designed to determine whether placenta ingestion would enhance the analgesia produced by vaginal/cervical probing.
We now report (a) a replication of the finding that placenta ingestion enhances morphine-induced analgesia. and (b) further evidence that the analgesic effect of endogenous opiates is enhanced by placenta ingestion.

\section{METHOD}

\section{Subjects}

Sixteen female Sprague-Dawley albino nulliparae. purchased from the Charles River Breeding Laboratories (Kingston, NY), were raised and tested at the Institute of Animal Behavior. The rats were 164 to 195 days of age. and were maintained in a colony on a reverse 14-on/10-off light cycle, with the light phase beginning at $1930 \mathrm{hr}(\mathrm{EST})$. The rats were housed individually in $30 \times 18 \times 18-\mathrm{cm}$ hanging wire mesh cages, and except during testing had free access to food (Purina Rat Chow) and water. Only rats willing to eat both placenta and ground beef were used. Approximately $50 \%$ of the rats pretested were spontaneously placentophagic. The proportion of placentophages is consistent with that previously reported for rats purchased from this breeder [6]. Each rat was exposed to placenta for $20 \mathrm{~min}$ on 3

${ }^{1}$ Requests for reprints should be addressed to Dr. Mark B. Kristal, Department of Psychology, SUNY at Buffalo, Buffalo, NY 14260. 
consecutive days; this was sufficient to induce her to e.dt 3-4 $\mathrm{g}$ during the 20 -min period. On the third day, after placenta exposure, each rat was presented with ground beef. All the rats ate beef on this presentation. Beef was presented again on each of the following two days to equalize the number of beef and placenta exposures, and to ensure that the rat would eat 3-4 g during a $20-\mathrm{min}$ period.

\section{Apparatus}

Pain thresholds were assessed by means of a tail-flick test $[1,3]$. We used an IITC Model 33 Tail Flick Analgesia Meter, which delivered heat to the rat's tail while the rat was restrained in a $5 \times 21-\mathrm{cm}$ opaque polyvinyl chloride tube. The movement of the tail out of the stimulus field activated a photoelectric cell which then shut off a latency timer. The latency, in seconds, for the tail-flick response to occur was the dependent variable. The sensitivity of the system could be varied by changing the intensity of the heat and the sensitivity of the photoelectric cell. The calibrations on the instrument were in arbitrary units, but were set so that the device produced an average tail-flick latency, in normal control rats, of about $4.5 \mathrm{sec}$ (beam intensity setting $=95$ ).

Vaginal/cervical stimulation was applied by probing the vaginal cervix with a glass rod protruding from the barrel of a glass $1 \mathrm{cc}$ tuberculin syringe. The rod was spring loaded and calibrated to deliver $75 \mathrm{~g}$ of pressure [2]. Stimulation was applied continuously until a tail-flick response occurred or until $15 \mathrm{sec}$ had elapsed, to prevent tissue damage to the tail.

\section{Procedures}

The 16 rats were evenly divided into two groups: tail-flick latency was determined in one group after they had ingested $1.5 \mathrm{~g}$ of placenta. and in the other after they had ingested 1.5 $\mathrm{g}$ of ground beef.

The placenta used was obtained surgically from Day-21 pregnant donors. Techniques for obtaining, storing, and presenting rat placenta have been described in detail elsewhere [5,7]. The ground beef was obtained from a local retail market, and treated identically to the placenta.

Vaginal smears were obtained daily, at the end of the light phase of the cycle, for the 4 days preceding testing, as well as on the day of testing. Rats were assigned to various groups so that each group contained the same proportion of subjects in diestrus $(0.75)$.

All testing was conducted on one day, and began $30 \mathrm{~min}$ after the beginning of the dark phase of the light/dark cycle (1000 hr EST). Food was removed from the rat's cage $2 \mathrm{hr}$ before it was tested.

Each test consisted of 4 tail-flick latency trials, separated by 5-sec intervals; the mean of these trial scores was used as the test score. First, each rat was given a series of pre-feeding tests, consisting of a baseline tail-flick test (Baseline Pre); a test conducted during vaginal/cervical stimulation (VS); a test conducted $1 \mathrm{~min}$ after the termination of vaginal/cervical stimulation (VS+1); and a test conducted $10 \mathrm{~min}$ after the termination of vaginal/cervical stimulation (VS+10). Next, each rat was exposed for $20 \mathrm{~min}$ to either $1.5 \mathrm{~g}$ placenta or $1.5 \mathrm{~g}$ ground beef. Immediately afterward, a post-feeding series of tests was conducted, maintaining the same sequence and time course as the pre-feeding battery of tests (Baseline Post, VS. VS +1 , VS +10 ). Finally, for verification of the enhancing effect of placenta ingestion on morphine-induced analgesia, as reported earlier [7], each rat was injected with a threshold dose of morphine sulfate (3

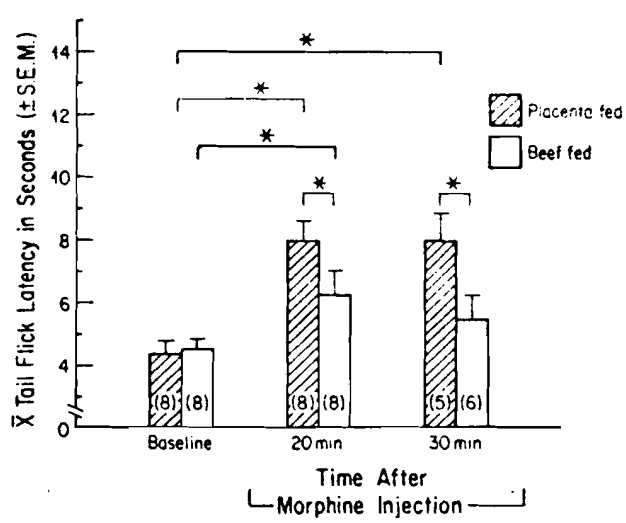

FIG. 1. Mean tail-flick latencies ( \pm S.E.M.) of placenta-fed and beef-fed rats 20 and $30 \mathrm{~min}$ after an injection of morphine sulfate ( 3 $\mathrm{mg} / \mathrm{kg}$, IP). The number in parentheses represents $\mathrm{n}$ for that group. $*=p<0.05$

$\mathrm{mg} / \mathrm{kg}, \mathrm{IP})$, and tested for tail-flick latency $20 \mathrm{~min}$ and $30 \mathrm{~min}$ later. The decision to conduct a 30 -min test was made after 3 rats had already passed the 30 -min point, thereby reducing the number of available subjects by three.

\section{RESULTS}

All the rats ate all the placenta or beef they were given. Although the morphine test was conducted last, we report the results of that test first, since those results confirm the previous finding that placenta ingestion enhanced opiatemediated analgesia. As seen in Fig. 1, the morphine-treated rats that had eaten placenta showed significantly longer tail-flick latencies than did the morphine-treated rats that had eaten beef, at both 20 and $30 \mathrm{~min}$ after injection. $F(2,24)=12.65, p<0.01$. Furthermore, the tail-flick latensies of the beef-fed rats, which had been significantly higher than baseline at $20 \mathrm{~min}$ (Newman-Keuls, $p<0.05$ ), returned to baseline range by $30 \mathrm{~min}$ (Newman-Keuls, $p>0.05$ ).

The data from the main experiment (summarized in Fig. 2) were analyzed first as a 3-way ANOVA (Food [Placenta, Beef] $\times$ Condition [Prefeeding. Postfeeding] $\times$ Test $)$, and subsequently probed for simple effects with 1-way ANOVAs and Newman-Keuls analyses. The 3-way ANOVA revealed a significant 3-way interaction, $\mathrm{F}(3,42)=5.43, p<0.005$.

In the Prefeeding condition, there were no differences between the placenta group and the beef group on any of the four tests: for the Food $\times$ Test interaction, $F(3.68)<1.0$ However, in this condition there was an effect of test. $\mathrm{F}(3,42)=63.65, p<0.01$, in that vaginal/cervical stimulation (VS) produced a significant elevation in tail-flick latency (Prefeeding/Both Foods/Baseline, mean $=4.27 \pm 0.15 \mathrm{sec}$; Prefeeding $/$ Both Foods/VS, mean $=11.29 \pm 0.69 \mathrm{sec}$ ), NewmanKeuls, $p<0.05$.

In the Postfeeding series of tests, the tail-flick latencies during vaginal/cervical stimulation in the placenta-fed rats (Postfeeding/Placenta/VS, mean $=12.33 \pm 1.17 \mathrm{sec}$ ) were significantly greater than those in beef-fed rats (Postfeeding/Beef/VS, mean $=9.99 \pm 1.03 \mathrm{sec}$ ), $F(1.53)=4.99 . p<0.05$ The tail-flick latencies during vaginalicervical stimulation in the placenta-fed rats (Postfeeding/Placenta/VS, mean $=12.33 \pm 1.17$ sec) were significantly greater than those produced in the same 


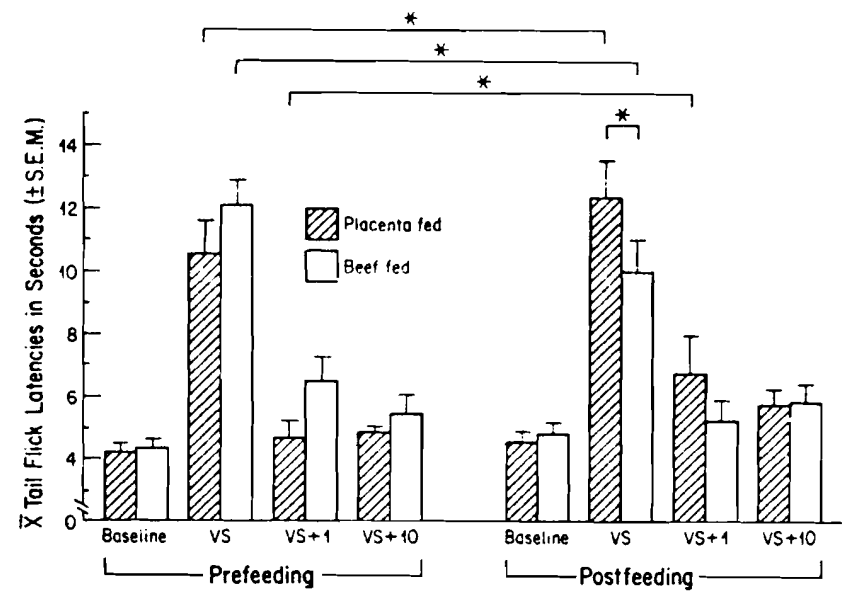

FIG. 2. Mean tail-flick latencies ( \pm S.E.M.) of placenta-fed and beef-fed rats before and after feeding. as measured before, during, and $1 \mathrm{~min}$ and $10 \mathrm{~min}$ after the application of vaginal/cervical stimulation. $\left(\mathrm{n}=8\right.$ : group; ${ }^{*}=p<0.05$ ).

rats before they had eaten the placenta (Prefeeding Placen$\mathrm{ta} / \mathrm{VS}$, mean $=10.45 \pm 1.14 \mathrm{sec}) . F(1.53)=8.15 . p<0.01$. The Prefeeding and Postfeeding baselines, however. were not different, $F(1.53)<1.0$.

In the placenta-fed group, the effect of placenta ingestion on analgesia produced by vaginal/cervical stimulation persisted after the termination of vaginal/cervical stimulation: the Postfeeding/Placenta/VS +1 latencies (mean $=6.69 \pm 1.26$ sec) were significantly longer than the Prefeeding/Placen$\mathrm{ta} / \mathrm{VS}+1$ latencies (mean $=4.65 \pm 0.62 \mathrm{sec}) . \quad F(1.53)=9.39$, $p<0.01$. There were no statistically significant differences between placenta-fed and beef-fed rats at VS +10 , nor was ,there a statistically significant difference within either food group between the Prefeeding and Postfeeding conditions at VS +10 .

In the beef-fed group, the increased tail-flick latencies produced by vaginal/cervical stimulation before feeding (Prefeeding/Beef $/$ VS. mean $=12.12 \pm 0.71 \mathrm{sec}$ ) were significantly greater than those produced during vaginal/cervical stimulation after feeding (Postfeeding/Beef $/ \mathrm{VS}$, mean $=9.99 \pm 1.03$ sec), $F(1,53)=10.28, p<0.01$

The 15-sec ceiling artificially reduced the mean latency of the Placenta group during vaginal/cervical stimulation in the Postfeeding condition. A significantly greater number of the trials in this group reached the 15 -sec ceiling (19 of 32) than had in the Prefeeding condition (11 of 32), Wilcoxon Test (on the change, from Pre to Post, in the number of trials/rat that reached $15 \mathrm{sec}), T=1, p<0.05$. The number of trials reaching ceiling among beef-fed rats did not change significantly from the Prefeeding condition (15 of 32) to the Postfeeding condition ( 9 of 32), Wilcoxon Test, $\mathrm{T}=5, p>0.05$.

\section{DISCUSSION}

The earlier finding [7] that placenta ingestion enhanced analgesia produced by an injection of an exogenous opiate was replicated despite some major differences in procedure: (a) albino rather than hooded rats were used: (h) the rats were tested during the dark phase rather than the light phase of the light/dark cycle; (c) a different tail-flick testing instrument was used: (d) placenta was eaten $35 \mathrm{~min}$ before. rather than immediately after. the morphine injection: and (e) the experiment was conducted in a different laboratory from the one in which the original experiment was run.

The effect of placenta ingestion on analgesia produced by vaginal/cervical stimulation is consistent with the documented effect of placenta ingestion on opiate-mediated analgesia [7]. Rats fed placenta showed a greater degree and longer duration of analgesia than did rats fed nothing (Prefeeding condition). or beef

The analgesia produced in beef-fed rats during the Postfeeding/Beef/VS test was significantly less than that produced in the same rats during the Prefeeding/Beef/VS test (see Fig. 2). Two factors can account for this decline. First. ingestion has been shown to lower pain thresholds [8]. and second. repeated (or continuous) vaginal probing has been observed to produce adaptation (or habituation) in that prolonged application of vaginal/cervical stimulation leads to diminishing analgesia levels [2]. It is important to note that in the present experiment placenta ingestion not only protected vaginal-stimulation-induced analgesia from diminishing. but produced a significant increase in analgesia from the Prefeeding/VS to the Postfeeding/VS tests.

Our results suggest, as did the previous report [7]. that although placenta ingestion enhances opiate-mediated analgesia. placenta ingestion itself does not produce analgesia. The first reason for drawing this conclusion in the present study is that the Postfeeding baseline tail-flick latencies for placenta-fed rats were not longer than the Prefeeding baseline latencies. Second, although the enhancement of morphine analgesia was still detectable $45 \mathrm{~min}$ after placenta ingestion ( $30 \mathrm{~min}$ after morphine injection), no analgesia was detectable at VS +10 (approximately $25 \mathrm{~min}$ after placenta ingestion), despite the fact that the enhancing effect of placenta ingestion had already been observable 10 min earlier.

Kristal et al. [7] speculated that. for the mother. enhancement of opiate analgesia may be a significant consequence of ingesting placenta and amniotic fluid at delivery. Although placenta becomes available to the mother only after the fetus emerges, amniotic fluid becomes available earlier. and preliminary results from our laboratory indicate that ingestion of amniotic fluid, too, enhances analgesia. The demonstration that placenta ingestion enhances analgesia produced by vaginal/cervical stimulation may also have special relevance for the natural situation, since vaginal/cervical mechanical stimulation occurs normally during passage of the fetus through the birth canal.

\section{ACKNOWLEDGEMENTS}

We thank Seymour Axelrod and Ed Katkin for their helpful comments on an earlier version of this paper.

\section{REFERENCES}

1. Bolles, R. C. and M. S. Fanselow. Endorphins and behavior. Annu Rev Psychol 33: 87-101. 1982.
2. Crowley, W. R., R. Jacobs, J. Volpe, J. F. Rodriguez-Sierra and B. R. Komisaruk. Analgesic effect of vaginal stimulation in rats: Modulation by graded stimulus intensity and hormones. Physiol Behav 16: 483-488, 1976. 
3. D'Amour, F. E. and D. L. Smith. A method for determining loss of pain sensation. J Pharmacol Exy Ther 72: 74-79, 1941.

4. Komisaruk, B. R. and J. Wallman. Antinociceptive effects of vaginal stimulation in rats: neurophysiological and behavioral studies. Brain R''s 137: 85-107. 1977.

5. Kristal, M. B. Placentophagia: A hiobehavioral enigma (or $D_{1}$ gustibus non disputandum est). Neurosci Biobehav R(v 4: 141$150,1980$.

6. Kristal, M. B. and G. C. Graber. Placentophagia in nonpregnant rats: Influence of estrous cycle stage and birthplace. Physiol Bchav 17: 599-605. 1976.

7. Kristal, M. B., A. C. Thompson and H. L. Grishkat. Placenta ingestion enhances opiate analgesia in rats. Physiol Bchav 35: $481-486,1985$
8. MeGivern. R. F. and G. G. Berntson. Mediation of diurnal flistuations in pain sensitivity in the rat by food intitie patterns: reversal by naloxone. Sciche' 210: 210-211, 1480.

9. Steinman. J. L., L. A. Roberts and B. R. Komisaruk. Evidence that endogenous opiates contribute to the mediation of vaginal stimulation-produced anti-nociception in rats. Ses Viaroser Abser 8: 47, 1982.

10. Watkins, L. R., D. A. Cobelli. P. Faris. M. D. Aceto and D. J. Mayer. Opiate vs. non-opiate footshock-induced analgeia (FSIA): The body region shocked is a critical factor. Brain Re's 242: 299-308, 1982. 